PAPER

\title{
HIV leucoencephalopathy and TNF $\alpha$ expression in neurones
}

\author{
K Rostasy, L Monti, S A Lipton, J C Hedreen, R G Gonzalez, B A Navia
}

J Neurol Neurosurg Psychiatry 2005;76:960-964. doi: 10.1136/jnnp.2004.036889

See end of article for authors' affiliations ....................

Correspondence to: Dr B Navia, Laboratories of Research in Psychiatry, Tufts-New England Medical Center, 75 Kneeland Street, Boston, MA 02111, USA;

BNavia@tufts-nemc.org

Received 18 January 2004 Revised version received 7 September 2004 Accepted

15 September 2004

\begin{abstract}
Background: Human immunodeficiency virus (HIV) leucoencephalopathy (HIVL) is an uncommon and rapidly progressive form of AIDS dementia complex (ADC) that has remained poorly understood. Tumour necrosis factor $\alpha(T N F \alpha)$, which has been implicated in the pathogenesis of $A D C$, is predominantly localised in macrophages in the HIV infected brain, although in vitro studies indicate that neurones can express this cytokine.

Objective: To examine the clinical/neuroradiological features of HIVL and the expression of TNF $\alpha$ in HIVL. Methods: Six patients who presented with rapidly progressive dementia within four to 12 weeks of the primary manifestation of their HIV infection were evaluated. Clinical history, treatment regimens, and imaging studies were reviewed, and brain samples from three of the patients were studied by means of immunohistochemistry.

Results: Imaging studies showed diffuse bilateral deep white matter changes in all six patients. Clinical and imaging abnormalities improved in five of the six patients within weeks after initiation of antiretroviral treatment. Brain biopsies of two showed pronounced microglia/macrophage activation, but only scant viral protein (gp41) expression. Staining for TNF $\alpha$ was found in microglia/macrophages, and surprisingly, in neurones also. Postmortem analysis of a third patient also showed TNF $\alpha$ expression in neurones of the frontal cortex and basal ganglia.

Conclusion: This study provides the first demonstration of staining for TNF $\alpha$ in the neurones of the HIV infected brain, and suggests that the process underlying this rapidly progressive form of ADC may reflect indirect mechanisms mediated by host factors, particularly TNF $\alpha$.
\end{abstract}

$\mathrm{H}$ uman immunodeficiency virus (HIV) infection is known to cause brain injury and neurocognitive impairment, variously termed HIV associated dementia or AIDS dementia complex (ADC), and primarily affecting areas of mental processing, behaviour, and motor control..$^{1-3}$ Although usually considered a late complication, for reasons that have remained unclear, it can present as the sole or primary manifestation of HIV infection. ${ }^{4}$ Onset in most subjects is typically insidious, and the course either slowly progressive or static. Less often, subjects can show rapid progression towards severe neurological impairment, and rarely a rapidly progressive form has been reported to occur in association with extensive deep white matter (DWM) lesions, a poorly understood disorder that has been described as HIV leucoencephalopathy (HIVL). ${ }^{5}$

The pathological features are predominantly localised to the DWM and subcortical grey matter, and include pallor of the white matter, multinucleated cell infiltration in more severe cases, and collections of infected or activated macrophages. ${ }^{136}$ In general, the extent of inflammation correlates with the severity of ADC. Neuronal loss, apoptosis, and synaptic dendritic injury have also been described..$^{7-10}$

The most commonly reported abnormality on cranial magnetic resonance imaging (MRI) or computed axial tomography is the presence of cerebral atrophy. ${ }^{11}{ }^{12}$ Volumetric loss in the cortical and subcortical regions, particularly the caudate, has been found to correlate in some reports with the degree of cognitive impairment. ${ }^{13}$ Abnormalities in the white matter in HIV encephalitis consist of either patchy or diffuse increases in $\mathrm{T}_{2}$ signals, but are generally less common. ${ }^{12}$ It is of interest that similar changes have been seen in reversible posterior leucoencephalopathy, which has been attributed to alterations in the blood-brain barrier (BBB). ${ }^{14-16}$

It is widely accepted that HIV associated brain injury is probably caused by indirect mechanisms, rather than the infection of neurones or glial cells. Recent studies have suggested that the pathogenesis of this disorder may be related to complex interactions of host ( $\mathrm{TNF} \alpha$, quinolinate, inducible nitrous oxide synthase, and stromal derived factor $1 \alpha)$ and viral factors (gpl20, Tat, and gp4l), leading to neuronal injury and apoptosis. ${ }^{17-22}$ In fact, the number of activated macrophages has been shown to be a better correlate of ADC than the number of infected cells. ${ }^{23}{ }^{24}$ Among the different host factors believed to contribute to the pathogenesis of the disorder, accumulating evidence indicates that $\mathrm{TNF} \alpha$ plays a central role. It is significantly raised in the HIV infected brain and has been shown to correlate with ADC severity and the degree of immunoactivation. ${ }^{25}{ }^{26}$ It is predominantly localised to perivascular microglia/macrophages, but can also be found in astrocytes. ${ }^{27}$ In vitro studies have shown that it can lead to neuronal apoptosis, potentiate the neurotoxic effects of HIV-1 proteins (gpl20 and Tat), and can be expressed in neurones..$^{19} 2027$

Previous studies have shown that zidovudine or AZT (3'azido-3' -deoxythymidine) can reverse some of the neurocognitive deficits associated with HIV infection, ${ }^{29}$ and more recently, combined potent antiretroviral treatments have been shown to benefit neurocognitive impairment. However, despite adequate viral suppression in the periphery, $30-40 \%$ of HIV infected subjects will develop some degree of neurocognitive impairment. ${ }^{30}$

Here, we describe the clinical course, neuroimaging findings, and treatment response of six patients who developed a rapidly progressive dementia associated with

Abbreviations: ADC, AIDS dementia complex; AZT, 3'-azido-3'deoxythymidine; BBB, blood-brain barrier; CSF, cerebrospinal fluid; DWM, deep white matter; HIV, human immunodeficiency virus; HIVL, human immunodeficiency virus leucoencephalopathy; MRI, magnetic resonance imaging; PML, progressive multifocal leucoencephalopathy; $\mathrm{TNF} \alpha$, tumour necrosis factor $\alpha$ 
diffuse bilateral changes in the white matter, consistent with HIVL. All six subjects responded rapidly to either AZT alone or combined antiretroviral treatments. Furthermore, brain samples from three of these patients showed TNF $\alpha$ staining in the neurones. This is the first report of the localisation of TNF $\alpha$ to neurones in the HIV infected brain.

\section{METHODS \\ Patients}

Between 1993 and 1998, 80 patients were referred to the neuro-HIV services at the Massachusetts General Hospital, Beth Israel Deaconess Medical Center, New England Medical Center (NEMC, Boston, USA) and Lemuel Shattuck Hospital (Jamaica Plain, Massachusetts, USA). Six patients who presented with rapidly progressive dementia as the primary AIDS defining illness and diffuse $\mathrm{T}_{2}$ signal changes in the DWM on MRI studies were identified (table 1). All patients were evaluated for other potential causes of changes in mental status. The case histories of two patients are described below.

\section{Radiological studies}

MRI studies ( $\mathrm{T}_{1}, \mathrm{~T}_{2}$, and proton density sequences) at the onset of clinical symptoms and after onset of treatment were reviewed. In five of the six cases, MRI scans performed before and during treatment were available.

\section{Immunohistochemistry}

Paraffin wax embedded postmortem material was available from patient 6 two years after he presented with rapid onset of dementia. Brain biopsies from the frontal cortex and adjacent DWM were performed in patients 4 and 5 (table 1 ). All three specimens were collected, paraffin wax embedded, and evaluated at the New England Medical Center (Boston, USA) between 1996 and 1998. Histopathological evaluation revealed no inclusion bodies and was not suggestive of cytomegalovirus infection or progressive multifocal leucoencephalopathy (PML). Serial $7 \mu \mathrm{m}$ sections were cut and mounted on precleaned Superfrosted (Fisher, Scientific, Pittsburgh, Pennsylvania, USA) slides. The sections were dewaxed and rehydrated using xylene and graded changes of ethanol. Antigen retrieval was achieved by autoclaving the slides in buffer (0.01M EDTA) for six minutes. ${ }^{31}$ Antibodies to the following antigens were used: gp4l (1/100 dilution; monoclonal; Genetic Systems, Redmond, Washington, USA), $\mathrm{TNF} \alpha$ ( $1 / 500$ dilution; polyclonal; Sigma, St Louis, Missouri, USA), TNF $\alpha$ (1/1000; monoclonal; R\&D, Minneapolis, Minnesota, USA), HLA-DR (1/1000 dilution; monoclonal; ENZO, Farmingdale, New York, USA), and glial fibrillary acidic protein (1/30 dilution; Dako, Carpinteria, California,

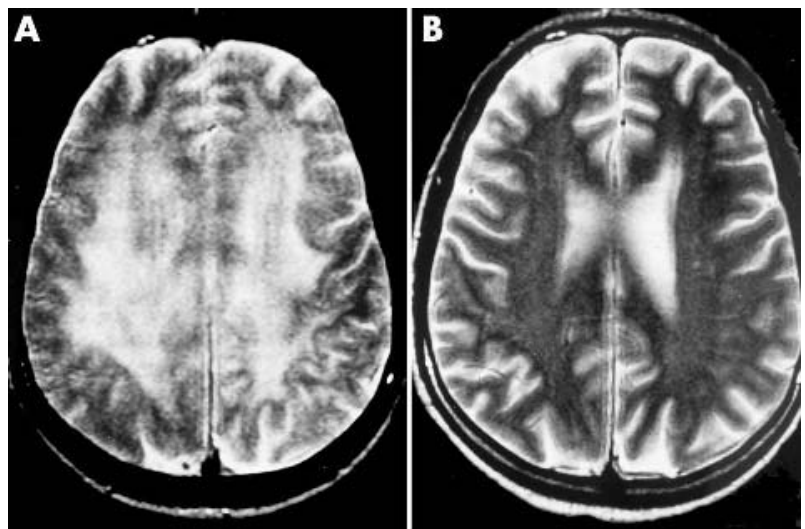

Figure $1 \quad T_{2}$ weighted axial magnetic resonance images of patient 1 (A) before and (B) after antiretroviral treatment showing substantial improvement of the deep white matter abnormalities.

USA). All antibodies were diluted in 5\% bovine serum albumin. ABC kits (Vector, Burlington, California, USA) were used for the secondary antibody and the streptavidinperoxidase label. Slides were then developed in 3,3'diaminobenzidine- $\mathrm{H}_{2} \mathrm{O}_{2}$ (Sigma) solution and counterstained with Harris's haematoxylin. A lymph node from an HIV positive patient was used as a positive control. The primary antibody was omitted as an internal control. Tissue from the normal brain of a 76 year old man, who died of heart failure, was used as a negative control. Peptide blocking studies using recombinant $\mathrm{TNF} \alpha$ protein (Boehringer Mannheim, Germany) were carried out to confirm the specificity of the polyclonal and monoclonal anti-TNF $\alpha$ antibodies. TNF $\alpha$ peptide (1/100 dilution; R\&D Systems) was preincubated with the polyclonal or monoclonal TNF $\alpha$ antibody for four hours and then applied to sections from the postmortem case (patient 6). All sections were stained with Luxol-Fast-Blue and haematoxylin and eosin to assess myelin pallor, multinucleated giant cells, and microglial nodule formation. The degree of staining was rated semiquantatively as absent, mild (up to five positive cells/high power field), moderate (five to 20 positive cells), or prominent (more than 20 positive cells).

\section{RESULTS}

From 1993 to 1998, six patients were identified who presented with rapid progressive cognitive and motor decline over a period of four to 12 weeks, consistent with ADC stage 2 or greater, as their initial AIDS defining illness (table 1). Cranial MRI studies showed extensive, bilateral, confluent

Table 1 Clinical features, antiretroviral therapy, and time interval between the first and second MRI study of the brain in six patients with HIV leucoencephalopathy

\begin{tabular}{|c|c|c|c|c|c|c|}
\hline Patient & Age/sex & $\begin{array}{l}\text { CD4 count } \\
\left(\times 10^{6} / \mathrm{I}\right)\end{array}$ & Clinical presentation & Drug treatment & $\begin{array}{l}\text { Time interval to } 2 \text { nd } \\
\text { MRI and CD4 count }\end{array}$ & Biopsy results \\
\hline 1 & $31 / M$ & 105 & $\begin{array}{l}\text { Depression for } 6 \text { months, } \\
\text { followed by confusion, falls, } \\
\text { leg weakness for } 3 \text { months }\end{array}$ & AZT $600 \mathrm{mg} /$ day & 5 weeks $/ 375$ & - \\
\hline $2^{*}$ & $42 / M$ & 80 & $\begin{array}{l}\text { Failing memory, frequent } \\
\text { falls for } 3 \text { months }\end{array}$ & AZT 800 mg/day & 12 weeks $/ 567$ & - \\
\hline 3 & $41 / M$ & 160 & Memory problems for 4 months & AZT 800 mg/day & 4 weeks/NK & - \\
\hline 4 & $40 / M$ & 98 & Mental decline for 10 weeks & AZT 1000 mg/day & 5 months $/ 439$ & Extensive TNF $\alpha, H L A-D R$ staining \\
\hline $5+$ & $46 / M$ & 110 & $\begin{array}{l}\text { Personality changes, memory } \\
\text { difficulties for } 2 \text { months }\end{array}$ & $\begin{array}{l}\text { AZT } 600 \mathrm{mg} / \text { day } \\
\text { Saquinavir }\end{array}$ & - & Extensive TNF $\alpha$, HLA-DR staining \\
\hline 6 & $33 / M$ & $<50$ & Confusional state for 4 weeks & $\begin{array}{l}\text { AZT } 600 \mathrm{mg} / \text { day } \\
\text { D4T } 60 \mathrm{mg} / \text { day }\end{array}$ & 5 weeks $/ 170$ & $\begin{array}{l}\text { Necropsy: gp } 41, \mathrm{TNF} \alpha, \mathrm{HLA}-\mathrm{DR} \\
\text { staining }\end{array}$ \\
\hline
\end{tabular}

*Only patient 2 had neuropsychological testing at the time of clinical presentation and after the symptoms had improved; tonly patient 5 had received AZT $600 \mathrm{mg} /$ day for a period of 3 months before the onset of cognitive decline.

AZT, AZT, 3'-azido-3'-deoxythymidine; HIV, human immunodeficiency virus; MRI, magnetic resonance imaging; NK, not known; TNF $\alpha$, tumour necrosis factor $\alpha$. 
abnormal $\mathrm{T}_{2}$ signals in the DWM of the centrum semiovale in the anterior and posterior regions in all six patients (fig l).

All six patients were started on antiretroviral treatment or had previous treatment regimens modified (table 1). AZT was included in all regimens and was given in a range of $600 \mathrm{mg} /$ day to $1000 \mathrm{mg} /$ day. In four patients, it was the only drug administered. All patients showed pronounced clinical improvement over the following weeks. Subsequent MRI studies showed improvement, with reduced white matter signal abnormalities in five of the six patients. Patient 5 had no follow up study. The time interval between the MRI study before antiretroviral treatment and the subsequent scan was four to five weeks in cases 1, 3, and 6 and three and five months in cases 2 and 5, respectively (table 1). The case histories of two patients are described below.

\section{Case 1 (patient 1)}

A 31 year old man presented with a six month history of abdominal pain, weight loss of $9 \mathrm{~kg}$, and mood changes. Gastritis and depression were diagnosed and antidepressants were commenced with good response. However, three months later, he developed a precipitous decline in his cognitive abilities. Subsequently, he was readmitted with frequent falls, confusion, and double incontinence. His neurological examination revealed that he was orientated to his name but not time and place. He was only able to follow a one step command. He showed generalised weakness and symmetrical hyper-reflexia, with extensor bilateral plantar responses. The history and neurological findings were consistent with a diagnosis of ADC stage 3, based on the MSKCC classification. ${ }^{32}$ Cerebrospinal fluid (CSF) studies were remarkable for a lymphocytic pleocytosis $\left(9 \times 10^{6}\right.$ white blood cells/litre, $96 \%$ lymphocytes, CSF protein $660 \mathrm{mg} / \mathrm{litre}$, CSF glucose $690 \mathrm{mg} / \mathrm{litre}$, serum glucose $1030 \mathrm{mg} /$ litre); Gram stain, cultures, cryptococcal antigen, VDRL, cytology, and toxicology screen were normal. His chest $x$ ray and Mantoux test were normal. His HIV screen, previously negative, was positive, and his CD4 count was $105 \times 10^{6}$ /itre. His cranial MRI scan showed diffuse bilateral increased $\mathrm{T}_{2}$ signals in the cerebral white matter, in addition to increased signal in the internal capsule and brainstem (fig lA). The patient was started on AZT $600 \mathrm{mg} / \mathrm{day}$. Six weeks later, the patient was alert, oriented, able to walk, and performed all activities of daily living. He continued to have mild difficulties on tasks of sustained attention and showed mild distal weakness of his upper extremities, accompanied by brisk reflexes and extensor plantar responses, consistent with ADC stage 1. His AZT dose was increased to $1000 \mathrm{mg} /$ day. A subsequent cranial MRI scan five weeks after onset showed only minimal DWM $\mathrm{T}_{2}$ signal hyperintensities (fig $1 \mathrm{~B}$ ).

\section{Case 2 (patient 4)}

A 40 year old man presented to the neurological clinic (New England Medical Center, Boston, USA) with a 10 week history of mental decline. His relatives noted problems with attention and forgetfulness. Apart from a history of drug abuse, he had no medical problems. His neurological examination revealed no focal neurological signs, apart from a mild truncal ataxia. However, his attention span, short term memory, and finger tapping skills were greatly reduced. His HIV screen was positive and his CD4 count was $98 \times 10^{6}$ \% litre. The history and neurological findings were consistent with a diagnosis of ADC stage 2. CSF studies were unremarkable (no pleocytosis, CSF glucose $590 \mathrm{mg} /$ litre/ serum glucose $990 \mathrm{mg} / \mathrm{litre}$, Gram stain and cultures were normal). Chest $x$ ray revealed no signs of tuberculosis. He was started on antiretroviral treatment with AZT $600 \mathrm{mg} /$ daily. A week later, his condition worsened with increasing difficulties in walking and cognition. In view of the cranial MRI scan, which showed diffuse bilateral increased $T_{2}$ signals in the cerebral white matter, a brain biopsy of the frontal cortex and adjacent white matter was obtained primarily to exclude PML. The daily dose of AZT was increased to $1000 \mathrm{mg}$. Over the following six weeks the patient showed steady improvement. The MRI scan of the brain was repeated after five months and showed a pronounced improvement of the DWM abnormalities.
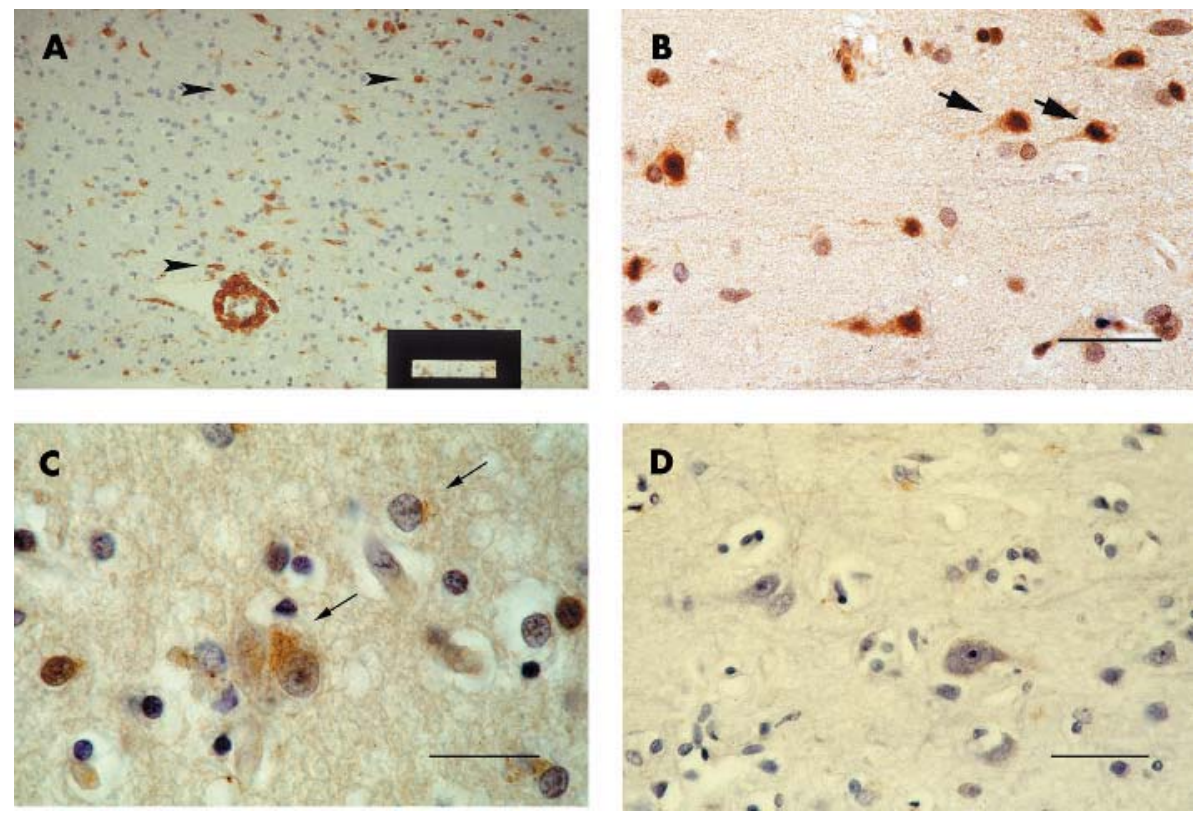

Figure 2 (A) Immunohistochemical staining for HLA-DR shows prominent activation of microglia/macrophages (arrows) in the biopsy of patient 4 (original magnification, $\times 20$ ). (B) Immunohistochemical staining with a rabbit polyclonal antibody against tumour necrosis factor $\alpha$ (TNF $\alpha$ ) in the biopsy of patient 4 shows staining of the cytoplasm of cortical neurones (arrows). (C) Staining with a monoclonal antibody to TNF $\alpha$ seen in the cytoplasm of neuronal cells (arrows) in the frontal cortex of patient 6 with severe AIDS dementia complex and human immunodeficiency virus encephalitis. (D) Preabsorption studies performed in adjacent sections from the frontal cortex of patient 6 . After preabsorption with TNF $\alpha$ peptide, staining with a monoclonal antibody against TNF $\alpha$ was negative (diaminobenzidine was used as the chromagen in all slides; all scale bars, $20 \mu \mathrm{m}$ ). 


\section{Immunohistochemistry}

Biopsies from the frontal brain region were obtained from patients 4 and 5. Patient 6 came to necropsy two years after his initial presentation. At the time of death, he was extremely undernourished and had acquired a fulminant pneumonia, but had no clinical evidence of a central nervous system infection. He was not orientated to his name, time, or place. He showed generalised weakness and was unable to walk. History and neurological findings were consistent with a diagnosis of ADC stage 4. Histopathological evaluation of all three specimens revealed no signs of cytomegalovirus infection or PML.

Immunohistochemical staining showed prominent immunoactivation in the DWM, as demonstrated by the number of HLA-DR positive macrophages/microglia in all three cases (fig 2A; patient 4). Only a few microglia/macrophages were positive for gp4l staining in the biopsy cases. Prominent expression of TNF $\alpha$ in macrophages/microglia was seen in the biopsy cases with a polyclonal antirabbit antibody. In addition, in both subjects, the cell body and axons of multiple neurones stained positive for TNF $\alpha$ with either the monoclonal or polyclonal antibody (fig 2B; patient 4). In the frontal cortex, hippocampus, and basal ganglia of patient 6 , $\mathrm{TNF} \alpha$ was detected in microglia/macrophages, and to a lesser degree in astrocytes. TNF $\alpha$ staining was also found in neurones of the frontal cortex and basal ganglia (fig 2C). In addition, the expression of gp4l and inducible nitrous oxide synthetase was prominent in all brain regions studied, accompanied by myelin pallor and astrocytosis in the DWM.

To assess the specificity of the neuronal expression of $\mathrm{TNF} \alpha$, we examined the cellular and regional expression of $\mathrm{TNF} \alpha$ in postmortem brain sections from 16 other HIV infected patients previously reported with various stages of cognitive impairment and without a clinical history of a focal central nervous system process. ADC staging was as follows: four subjects were stage 0 , five subjects were ADC stage 1 , three subjects were stage 2 , and four subjects were stage $3 / 4 .{ }^{23}$ None of these patients showed the radiographic pattern of white matter abnormalities described above. No further neuronal staining for TNF $\alpha$ was found in the subjects.

Peptide blocking studies were performed on serial brain sections from patient 6 . Staining for TNF $\alpha$ using either antibody was abolished by the blocking peptide in macrophages/microglia, astrocytes, and neurones (fig 2D).

\section{DISCUSSION}

Our study examines the clinical presentation of six patients with acute/subacute and reversible cognitive motor decline as their main AIDS defining illness, all of whom had similar findings on cranial MRI, characterised by diffuse, bilateral $\mathrm{T}_{2}$ hyperintense signal changes in the DWM. The striking association of white matter abnormalities, the distinct clinical course, and the rapid response to antiretroviral drug treatment suggest that these patients may have a unique form of ADC.

In a previous study, Bouwman et al described the clinical characteristics of rapid progressors and non-progressors with HIV dementia. ${ }^{33}$ Rapid progressors showed a decline in neurocognitive function over months compared with the non-progressors, who had more stable disease. However, several aspects distinguish these rapid progressors from our group of patients. Patients of the above mentioned study developed dementia towards the end of their illness and did not present with dementia as their AIDS defining illness. Furthermore, radiological features such as atrophy and white matter abnormalities did not differ between the rapid progressors and the non-progressors. Third, no differences were noted in antiretroviral treatment response between rapid progressors and non-progressors.
The term HIVL has been used previously to describe the pathological findings in the white matter of patients with AIDS, ranging from patchy isolated lesions to extensive bilateral and confluent white matter changes involving the midbrain and pons. Histological features include myelin pallor, astrogliosis with evidence of immune activation, and viral infection predominantly localised to microglia and macrophages. ${ }^{34}$

The pathophysiological basis of the reversible DWM changes in these patients is not well understood. Three studies implicate altered BBB function as an important underlying mechanism. Smith et al noted striking changes in the microvasculature, including mural thickening, increased cellularity, and enlargement of endothelial cells in patients with features of HIV encephalitis and leucoencephalitis. ${ }^{35}$ Two groups detected a significant accumulation of serum proteins in the cerebral white matter, consistent with breakdown of the BBB. ${ }^{36}{ }^{37}$

All patients in our present report showed rapid cognitive improvement soon after the introduction of antiretroviral treatment, accompanied by a reversal of DWM lesions. In contrast, in patients with the more slowly progressive form of ADC treated with antiretroviral drugs, restitution of cognitive functions tends to occur slowly and MRI changes do not improve substantially. ${ }^{38}$ One possible explanation might be that the prompt institution of antiretroviral treatment caused a decline in peripheral viral load and circulating inflammatory cytokine concentrations, leading to a reversal of $\mathrm{BBB}$ abnormalities and improvement in cognitive function.

Immunohistochemical studies of the two biopsies showed prominent HLA-DR expression but only mild viral protein (gp4l) expression, in contrast to the findings in the postmortem case. This observation raises the possibility that HIV proteins in the brain might not be an important factor in the acute or early stages of ADC compared with its later stages. Furthermore, in all three cases, prominent TNF $\alpha$ staining was seen in astrocytes and perivascular microglia/ macrophages of the DWM, consistent with previous reports. ${ }^{25} 2639 \mathrm{TNF} \alpha$ positive cells such as microglia/macrophages and astrocytes have a crucial role in the induction of astrocytosis, and may also play a role in alteration of the $\mathrm{BBB}^{30} 40$

The surprising finding of our study was the detection of $\mathrm{TNF} \alpha$ staining in neurones in all three subjects. Interestingly, Cowan et al showed that NT2 cells, which share morphological and functional features of mature primary neurones, were able to produce $\mathrm{TNF} \alpha$ upon stimulation with human $\mathrm{T}$ cell leukaemia virus 1 Taxl. ${ }^{41}$ Several other groups have reported that certain HIV virions and HIV proteins (gpl20 and Tat) can stimulate the cellular production of TNF $\alpha$ in macrophages, astrocytes, and neurones. ${ }^{42}{ }^{43}$ Further support for the notion that human neuronal cells can produce TNF $\alpha$ comes from a recent immunohistochemical study, in which prominent neuronal staining with antibodies to TNF $\alpha$ was found in cortical areas adjacent to the DWM lesions in preterm infants with periventricular leucomalacia. ${ }^{44}$ The reason why neurones produce $\mathrm{TNF} \alpha$ particularly under pathological conditions is at present unclear. One hypothesis is that TNF $\alpha$ is produced in an autocrine fashion, in an attempt to promote cell survival via activation of nuclear factor $\mathrm{\kappa B}$ and the upregulation of survival proteins..$^{26}{ }^{45}$

The results of our study suggest that certain HIV infected patients may be predisposed to develop a primary cytokine induced encephalopathy. Quasney et al found that the presence of the A allele at the $\mathrm{TNF} \alpha-308$ site in the promoter region was over-represented among adults with HIV dementia compared with those without dementia and healthy controls, suggesting that this locus may play a role in the pathogenesis of HIV dementia. ${ }^{46}$ In vitro studies have 
shown that the TNF2 allele increases the transcription of $\mathrm{TNF} \alpha$, consistent with the finding that homozygotes for the TNF2 allele have significantly raised concentrations of TNF $\alpha .{ }^{47}$ This raises the possibility that polymorphisms in the TNF $\alpha$ gene may predispose a subgroup of patients with HIV to a more rapid cognitive decline.

\section{CONCLUSION}

HIVL is a unique form of HIV associated brain injury, which is characterised by a more rapid onset of clinical symptoms and prominent, reversible white matter changes. Furthermore, we show evidence of TNF $\alpha$ expression in neurones in three patients, suggesting that the process underlying this rapidly progressive form of ADC may reflect indirect mechanisms mediated by host factors, particularly $\mathrm{TNF} \alpha$.

\section{ACKNOWLEDGEMENTS}

The authors thank Dr K Kuban and H Waibel for their encouraging thoughts and assistance. This work was partly supported by NIH grants R01 NS 36524 (BN), F32 NS10867 (KR), and P01 HD 29587 (SAL), and by awards from the Lifespan-Tufts-Brown Center for AIDS (BN) and the New England Medical Research Foundation $(\mathrm{BN})$.

\section{Authors' affiliations}

B A Navia, Tufts Neurology Program, New England Medical Center, 75 Kneeland Street, Boston, MA 02111 , USA

L Monti, J C Hedreen, Department of Psychiatry, New England Medical Center

K Rostasy, Paediatric Neurology, University of Göttingen, Robert-KochStr. 40, Göttingen 37073, Germany

R G Gonzalez, Department of Neuroradiology, Massachusettes General Hospital, Boston, MA 02111, USA

S A Lipton, Center for Neuroscience and Aging, The Burnham Institute, La Jolla, CA 92037, USA

Competing interests: none declared

\section{REFERENCES}

1 Navia BA, Jordan B, Price RW. The AIDS dementia complex I: clinical features. Ann Neurol 1986; 19:517-35.

2 Price RW, Brew B, Sidtis J, et al. The brain in AIDS: central nervous system HIV-1 infection and AIDS dementia complex. Science 1988;239:586-92.

3 Glass JD, Wesselingh SL, Selnes OA, et al. Clinical-neuropathologic correlation in HIV-associated dementia. Neurology 1993;43:2230-7.

4 Navia BA, Price RW. The acquired immunodeficiency syndrome dementia complex as the presenting sole manifestation of human immunodeficiency virus infection. Arch Neurol 1987:44:65-9.

5 Luer W, Gerhards J, Poser S, et al. Acute diffuse leukoencephalitis in HIV-1 infection. J Neurol Neurosurg Psychiatry 1994;57:105-7.

6 Wiley C, Achim C. Human immunodeficiency virus encephalitis is the pathological correlate of dementia in acquired immunodeficiency syndrome. Ann Neurol 1994;36:673-6.

7 Wiley C, Masliah E, Morey M, et al. Neocortical damage during HIV infection. Ann Neurol 1991;29:651-7.

8 Everall I, Luthert P, Lantos P. Neuronal loss in the frontal cortex in HIV infection. Lancet 1991;337:1119-21.

9 Masliah E, Achim C, Ge N. Spectrum of human immunodeficiency virusassociated neocortical damage. Ann Neurol 1992;32:321-9.

10 Petito CK, Roberts B. Evidence of apoptotic cell death in HIV encephalitis. Am J Pathol 1995; 146:1121-30.

11 Levy RM, Roesenbloem L, Perrett LV. Neuroradiological findings in AIDS: a review of 200 cases. AJR Am J Roentgenol 1986;147:977-83.

12 Smirniotopoulos JG, Koeller KK, Nelson AM, et al. Neuroimaging-autopsy correlations in AIDS. Neuroimaging Clin N Am 1997;7:615-37.

13 Aylward EH, Brettschneider PD, McArthur JC, et al. Magnetic resonance imaging measurement of gray matter volume reductions in HIV dementia. Am J Psychiatry 1995; 152:987-94.

14 Hinchey J, Chaves C, Appignani B, et al. A reversible posterior leukoencephalopathy syndrome. N Engl J Med 1996;334:494-500.

15 Berger JR, Nath A, Greenberg RN, et al. Cerebrovascular changes in the basal ganglia with HIV dementia. Neurology 2000;54:921-6.

16 Schaefer PW, Gonzalez RG, Hunter G, et al. Diagnostic value of apparent diffusion coefficient hyperintensity in selected patients with acute neurologic deficits. J Neuroimaging 2001;11:369-80.
17 Adams DC, Wildemann B, Sasaki M, et al. Immunologic NO synthase: elevation in severe AIDS dementia and induction by HIV-1gp 41. Science 1996;274:1917-20.

18 Wesselingh SL, Power C, Glass JD, et al. Intracerebral cytokine messenger RNA expression in acquired immunodeficiency syndrome dementia. Ann Neurol 1993;33:576-82.

19 Yeung MC, Pulliam L, Lau AS. The HIV envelope protein gp120 is toxic to human brain-cell cultures through the induction of interleukin- 6 and tumor necrosis factor. AIDS 1995;9:137-43.

20 Shi B, Raina J, Lorenzo A, et al. Neuronal apoptosis induced by HIV-1 Tat protein and TNF- $\alpha$ : potentiation of neurotoxicity by oxidative stress and implications for HIV-1 dementia. J Neurovirol 1998;4:281-90.

21 Kaul M. Lipton S. Chemokines and activated macrophages in HIV gpl20induced neuronal apoptosis. Proc Natl Acad Sci U S A 1999:96:8212-16.

22 Giulian D, Vaca K, Noonan CA. Secretion of neurotoxins of mononuclear phagocytes infected with HIV-1. Science 1990;250:1593-6.

23 Rostasy K, Monti L, Kneissl M, et al. HIV infection, iNOS expression and microglial activation: pathogenetic relationship to the AIDS dementia complex. Ann Neurol 1999;46:207-16.

24 Glass JD, Fedor $\mathrm{H}$, Wesselingh S, et al. Immunocytochemical quantitation of human immunodeficiency virus in the brain: correlations with dementia. Ann Neurol 1995;38:755-62.

25 Wesselingh SL, Takahashi K, Glass JD, et al. Cellular localization of tumor necrosis factor mRNA in neurological tissue from HIV-infected patients by combined reverse transcriptase/polymerase chain reaction in situ hybridization and immunohistochemistry. J Neuroimmunol 1997:74:1-8.

26 Rostasy K, Monti L, Yiannoutsos C, et al. NF-kB activation, TNF- $\alpha$ expression, and apoptosis in the AIDS dementia complex. J Neurovirol 2000;6:537-43.

27 New DR, Ma M, Epstein LG, et al. Human immunodeficiency virus type 1 Tat protein induces death by apoptosis in primary human neuron cultures. J Neurovirol 1997:3:168-73.

28 Talley A, Dewhurst S, Perry S. Tumor necrosis factor alpha induced apoptosis in human neuronal cells: protection by the antioxidant $\mathrm{N}$-acetylcysteine and the genes bcl-2 and crm-A. Mol Cell Biol 1995; 15:2359-66.

29 Schmitt FA, Bigley JW, McKinnis R, et al. Neuropsychological outcome of zidovudine (AZT) treatment of patients with AIDS and AIDS-related complex. N Engl J Med 1988;319:1573-8.

30 Sacktor N, Lyles RH, Skolasky R, et al. HIV-associated neurologic disease incidence changes: multicenter AIDS cohort study, 1990-1998. Neurology 2001:56:257-60

31 Hedreen JC, Mucci LA. Antigen retrieval for paraffin section immunocytochemistry with antibodies commonly used in studies of degenerative diseases. Abstr Soc Neurosci, 1995;21:1802.

32 Price RW, Brew BJ. The AIDS dementia complex. J Infect Dis 1998;158:1079-83.

33 Bouwman FH, Skoloasky RL, Hes D, et al. Variable progression of HIVassociated dementia. Neurology 1998;50:1814-20.

34 Budka H, Wiley CA, Kleihues P. HIV-associated disease of the nervous system: review of nomenclature and proposal for neuropathology-based terminology. Brain Pathol 1991;1:143-52.

35 Smith TW, DeGirolami U, Henin D, et al. Human immunodeficiency virus (HIV) leukoencephalopathy and the microcirculation. I Neuropathol Exp Neurol 1990:49:357-70.

36 Power C, Kong PA, Crawford TO, et al. Cerebral white matter changes in acquired human immunodeficiency syndrome dementia: alterations of the blood-brain barrier. Ann Neurol 1993;34:339-50.

37 Petito CK, Cash KS. Blood brain barrier abnormalities in the acquired immune deficiency syndrome: immunohistochemical localization of serum proteins to postmortem brains. Ann Neurol 1992;32:658-66.

38 Stout JC, Ellis RJ, Jernigan TL, et al. Progressive cerebral volume loss in human immunodeficiency virus infection: a longitudinal magnetic resonance imaging study. HIV neurobehavioural research center group. Arch Neurol 1998;55:161-8.

39 Seilhean D, Kobayashi K, He Y, et al. Tumor necrosis factor- $\alpha$, microglia and astrocytes in AIDS dementia complex. Acta Neuropathol 1997;93:508-17.

40 Fiala $M$, Looney DJ, Stins $M$, et al. TNF- $\alpha$ opens a paracellular route for HIV-1 invasion across the blood-brain barrier. Mol Med 1997;3:553-64.

41 Cowan EP, Alexander RK, Daniel S, et al. Induction of tumor necrosis factor in human neuronal cells by extracellular T-cell lymphotropic virus type 1 Tax. $J$ Virol 1997:71:6982-9.

42 Chen P, Mayne M, Power C, et al. The Tat protein of HIV-1 induces tumor necrosis factor-alpha production. Implications for HIV-1-associated neurological diseases. J Biol Chem 1997;272:22385-8.

43 Khanna KV, Yu XF, Ford DH, et al. Differences among HIV-1 variants in their ability to elicit secretion of TNF-alpha. J Immunol 2000;164:1408-15.

44 Kadhim HJ, Tabarki-Mlaiki B, De Prez C, et al. Cytokine immunoreactivity in cortical and subcortical neuronal centers in periventricular leukomalacia. Ann Neurol 2000;48:528.

45 Mattson MP, Culmsee C, Yu Z, et al. Roles of nuclear factor kappaB in neuronal survival and plasticity. J Neurochem 2000;74:443-56.

46 Quasney MW, Zhang Q, Sargent S, et al. Increased frequency of the tumor necrosis factor-alpha-308 A allele in adults with human immunodeficiency virus dementia. Ann Neurol 2001:50:157-62.

47 Wilson AG, Symons JA, McDowell TL, et al. Effects of a polymorphism in the human tumor necrosis factor alpha promoter on transcriptional activation. Proc Natl Acad Sci U S A 1997;94:3195-9. 